\title{
Hepatitis B virus infection and development of chronic kidney disease: a cohort study
}

\author{
Yun Soo Hong ${ }^{1 \dagger}$, Seungho Ryu ${ }^{2,3,4+}$, Yoosoo Chang 2,3,4, Miguel Caínzos-Achirica ${ }^{1,5,6,7}$, Min-Jung Kwon 2,8, Di Zhao', \\ Tariq Shafi ${ }^{1,9}$, Mariana Lazo ${ }^{1}$, Roberto Pastor-Barriuso ${ }^{10}$, Hocheol Shin ${ }^{11}$, Juhee Cho ${ }^{1,2,3^{*}}$ and Eliseo Guallar ${ }^{1 *}$
}

\begin{abstract}
Background: The effect of chronic hepatitis B virus (HBV) infection on the risk of chronic kidney disease (CKD) is controversial. We examined the prospective association between hepatitis B surface antigen ( $\mathrm{HBsAg}$ ) serology status and incident CKD in a large cohort of men and women.

Methods: Cohort study of 299,913 adults free of CKD at baseline who underwent health screening exams between January 2002 and December 2016 in South Korea. Incident CKD was defined as the development of an estimated glomerular filtration rate $(e G F R)<60 \mathrm{ml} / \mathrm{min} / 1.73 \mathrm{~m}^{2}$ and/or proteinuria.

Results: Over 1,673,701 person-years of follow-up, we observed 13,924 incident cases of CKD (3225 cases of eGFR $<60 \mathrm{ml} / \mathrm{min} / 1.73 \mathrm{~m}^{2}$ and 11,072 cases of proteinuria). In fully adjusted models comparing positive to negative HBsAg participants, the hazard ratio (HR, 95\% confidence interval) for incident CKD was $1.11(1.03-1.21 ; P=0.01)$. The corresponding HR for incident proteinuria and for eGFR $<60 \mathrm{ml} / \mathrm{min} / 1.73 \mathrm{~m}^{2}$ were $1.23(1.12-1.35 ; P<0.001)$ and $0.89(0.73-1.07 ; P=0.21)$, respectively. The associations were similar across categories of liver enzyme levels at baseline.

Conclusion: In this large cohort, HBsAg positive serology was associated with higher risk of incident CKD, and we provide novel evidence that this association was due to a higher incidence of proteinuria in HBsAg positive participants. Our study adds to the growing body of evidence suggesting that chronic HBV infection may be a contributor to the increasing incidence of CKD.
\end{abstract}

Keywords: Chronic kidney disease, Cohort study, Hepatitis B virus infection, Hepatitis B surface antigen, Proteinuria, Risk factors

\section{Background}

Chronic hepatitis B virus (HBV) infection is one of the major causes of liver cirrhosis and hepatocellular carcinoma worldwide [1]. In addition to liver disease, HBV infection has been associated with extra-hepatic complications [2]. For example, various forms of kidney injury have been described in relation to HBV, including membranous nephropathy, membranoproliferative glomerulonephritis, and polyarteritis nodosa [3].

\footnotetext{
*Correspondence: jcho@skku.edu; eguallar@jhu.edu

${ }^{\dagger}$ Yun Soo Hong and Seungho Ryu contributed equally to this work.

'Departments of Epidemiology and Medicine, and Welch Center for

Prevention, Epidemiology, and Clinical Research, Johns Hopkins University

Bloomberg School of Public Health, Baltimore, MD, USA

Full list of author information is available at the end of the article
}

HBV-associated nephropathy most commonly presents with proteinuria or nephrotic syndrome [4], which may be caused by immune complex deposition, by virus-induced immunologic responses [3], or by direct glomerular and tubular injury by HBV [5]. It is unclear, however, whether exposure to $\mathrm{HBV}$ is associated with an increased risk of chronic kidney disease (CKD).

Previous longitudinal studies from Taiwan, where HBV infection is endemic, and China showed that positive hepatitis B surface antigen ( $\mathrm{HBsAg}$ ) serology was associated with increased risk of incident CKD $[6,7]$ and end-stage renal disease (ESRD) [8]. However, incident CKD and ESRD were identified from claims data using International Classification of Diseases, Ninth or Tenth

C The Author(s). 2018 Open Access This article is distributed under the terms of the Creative Commons Attribution 4.0 International License (http://creativecommons.org/licenses/by/4.0/), which permits unrestricted use, distribution, and reproduction in any medium, provided you give appropriate credit to the original author(s) and the source, provide a link to the Creative Commons license, and indicate if changes were made. The Creative Commons Public Domain Dedication waiver (http://creativecommons.org/publicdomain/zero/1.0/) applies to the data made available in this article, unless otherwise stated. 
Revision (ICD-9 or ICD-10), rather than using biomarkers of kidney function or kidney damage. The presence of hepatitis B core (anti-HBc) antibodies, on the contrary, was not associated with a higher incidence of CKD over 5 years of follow-up in a Chinese population undergoing screening exams [9]. The results from cross-sectional studies were also inconsistent, with most studies showing no association between HBV infection and the prevalence of CKD and one study showing an inverse association [10-13].

Chronic liver disease patients with coexisting renal impairment tend to have poorer outcomes than those with preserved renal function [14]. Therefore, early detection of CKD is of particular importance in the long-term management and prognosis of patients with chronic liver disease. We thus aimed to evaluate the prospective association between HBV infection and incident CKD, defined using estimated glomerular filtration rate (eGFR) and proteinuria, in a large cohort of men and women with normal renal function at baseline who participated in regular health screening examinations in South Korea.

\section{Methods}

\section{Study population}

The Kangbuk Samsung Health Study is a cohort study of adult men and women who underwent annual or biennial comprehensive medical health examinations at the two Kangbuk Samsung Hospital Total Healthcare Centers located in Seoul and Suwon, South Korea.

$[15,16]$.

Among participants with at least one follow-up visit between January 1, 2002 and December 31, $2016(n=320,069)$, we excluded participants with any of the following conditions at baseline: prevalent CKD $(n=14,548)$, ultrasound evidence of chronic nephritis, structural kidney disease, kidney surgery, or kidney tumor, or kidney transplantation ( $n=1724)$; self-reported history of cancer $(n=3667)$; ultrasound findings of liver tumor, liver surgery, or liver transplantation $(n=198)$. After excluding 19,645 participants, the number of eligible participants was 300,424 (170,214 men and 130,210 women). We further excluded participants with missing information on HBsAg serology, eGFR, body mass index (BMI), fasting blood glucose, or systolic blood pressure at baseline $(n=301)$. The final sample included 299,913 participants (169,994 men and 129,919 women; Fig. 1).

This study was approved by the Kangbuk Samsung Hospital Institutional Review Board that waived the requirement for informed consent as we only used de-identified data obtained as part of routine health screening exams.

\section{Data collection}

As part of the comprehensive health exam, study participants provided detailed information on medical history, family history, medication use, smoking habits, alcohol

\begin{tabular}{|c|c|}
\hline \multicolumn{2}{|c|}{$\begin{array}{l}\text { Participants who underwent a comprehensive health screening exam from January } 1 \text {, } \\
2002 \text { to December } 31,2016 \text {, and had at least } 1 \text { follow-up visit }(n=320,069)\end{array}$} \\
\hline & $\begin{array}{l}\text { Exclusions }(\mathbf{n}=\mathbf{1 9 , 6 4 5}) \\
\text { - Prevalent chronic kidney disease }(\mathrm{CKD}) \text { by eGFR, proteinuria, or self- } \\
\text { reported history }(\mathrm{n}=14,548) \\
\text { - Ultrasound evidence of chronic nephritis, structural kidney disease, kidney } \\
\text { surgery including nephrectomy, kidney transplantation, kidney tumor, or } \\
\text { polycystic kidney disease }(\mathrm{n}=1,724) \\
\text { - History of cancer }(\mathrm{n}=3,667) \\
\text { - Ultrasound evidence of liver tumor, liver surgery, or liver transplantation }(\mathrm{n}= \\
198)\end{array}$ \\
\hline \multicolumn{2}{|c|}{ Participants eligible to be included in the cohort study $(n=300,424)$} \\
\hline & $\begin{array}{l}\text { Exclusions }(n=511) \\
\text { - Missing data on HBsAg }(n=111) \\
\text { - Missing data on eGFR }(n=67) \\
\text { - Missing data on body mass index }(n=18) \\
\text { - Missing data on fasting glucose at baseline }(n=4) \\
\text { - Missing data on systolic blood pressure at baseline }(n=259)\end{array}$ \\
\hline
\end{tabular}

Fig. 1 Flowchart of study participantsAbbreviations: CKD, chronic kidney disease; eGFR, estimated glomerular filtration rate; HBsAg, Hepatitis B surface antigen 
intake, physical activity, and socioeconomic status at each visit using a standardized self-administered questionnaire at each visit. Smoking categories were defined as never, former, and current smokers. Current alcohol intake was estimated in grams per day. Physical activity was categorized based on the frequency of moderate- or vigorous-intensity exercise per week $(<3$ or $\geq 3$ times per week). Education level was categorized as less than college degree and college degree or higher.

Anthropometric measurements, including height, weight, and blood pressure, were measured at each visit by trained staff members under standard conditions. BMI was calculated as weight in kilograms divided by height in meters squared $\left(\mathrm{kg} / \mathrm{m}^{2}\right)$. Hypertension was defined as systolic blood pressure $\geq 140 \mathrm{mmHg}$, diastolic blood pressure $\geq 90 \mathrm{mmHg}$, self-reported history of hypertension, or self-reported use of antihypertensive medication.

The presence of fatty liver disease was determined at each visit by abdominal ultrasonography, which was a routine part of the health exam for all participants. Experienced radiologists at each center performed the exam using LOGIQ $700 \mathrm{MR}$ machines with $3.5-\mathrm{MHz}$ transducers (GE, Milwaukee, WI, USA). Fatty liver disease was diagnosed if there was diffuse hyperechoic parenchyma compared to that of the kidney or spleen [17]. Cirrhosis diagnosis was based on the presence of coarse and inhomogeneous parenchyma, caudate hypertrophy, surface nodularity, signs of portal hypertension, or regenerative nodules on ultrasonography.

\section{Laboratory determinations}

At each visit, serum samples from all participants were tested for complete blood count, blood chemistry (including, but not limited to, renal function tests and liver function tests), and viral hepatitis serology, and urine samples were tested for presence of proteinuria.

Serum samples were analyzed for HBsAg using immunoradiometric assays (Radim, Via del Mare, Italy) in the Seoul center from 2002 to 2009 and in the Suwon center from 2002 to 2006, and using an electrochemiluminescent immunoassay (Modular E170; Roche Diagnostics) in both centers afterwards. A blood chemistry panel including alanine aminotransferase (ALT), aspartate aminotransferase (AST), gamma-glutamyl transferase (GGT), serum creatinine and serum glucose, was measured in fasting samples using Bayer Reagent Packs on an Advia 1650TM Autoanalyzer (Bayer Diagnostics, Medfeld, MA, USA) between 2002 and February 2010 at the Seoul center and between 2002 and September 2006 at the Suwon center, and on a Modular Analytics D2400 analyzer (Roche Diagnostics, Tokyo, Japan) in both centers afterwards.
Estimated GFR was calculated using the 4-variable Modification on Diet in Renal Disease Study equation, and CKD was defined as an eGFR $<60 \mathrm{ml} / \mathrm{min} / 1.73 \mathrm{~m}^{2}$ and/or the presence of proteinuria [18]. Diabetes was defined as a fasting serum glucose $\geq 126 \mathrm{mg} / \mathrm{dl}$, a self-reported physician diagnosis, or current use of insulin or other hypoglycemic agents.

Urine dipsticks (URiSCAN Urine test strips, YD Diagnostics) were used to measure urine protein semi-quantitatively for all participants and were reported in 6 grades (absent, trace, $1+, 2+, 3+$, and $4+$ ). Presence of proteinuria was defined as grade $1+$ or greater.

The Laboratory Medicine Department at Kangbuk Samsung Hospital has been accredited by the Korean Society of Laboratory Medicine (KSLM) and the Korean Association of Quality Assurance for Clinical Laboratories (KAQACL). The laboratory also participates in the survey proficiency testing provided by the College of American Pathologists (CAP).

\section{Statistical analysis}

Baseline variables were summarized by HBsAg status as number (proportion) for categorical variables and mean (standard deviation) or median (interquartile range) for continuous variables, and compared using $X^{2}$ tests, Student's t-tests, or signed-rank sum tests as appropriate.

Participants free of CKD at baseline were followed from the baseline visit until the development of CKD, or until the last screening visit. Development of CKD was evaluated at each visit based on the eGFR and the presence of proteinuria. Because the development of CKD was detected during a study visit but the exact date of its onset could not be determined, we used a parametric proportional hazards model to take into account this type of interval censoring (stpm command in Stata) [19]. The baseline hazard function was parametrized with restricted cubic splines in log time with four degrees of freedom. We estimated hazard ratios (HR) and 95\% confidence intervals (CI) for incident CKD comparing HBsAg positive with HBsAg negative participants. To control for potential confounders, we used 3 models with progressive degrees of adjustment: Model 1 was adjusted for age, sex, study center, and baseline eGFR; Model 2 was further adjusted for smoking status, alcohol intake, level of education, physical activity, and BMI; and Model 3 was further adjusted for the presence of hypertension, diabetes, and fatty liver disease. We created indicator variables for missing values for smoking status (5.7\%), alcohol intake (5.4\%), level of education (26.5\%), and physical activity (1.3\%). There were no missing values for the presence of hypertension, diabetes, and fatty liver disease. The same analyses were also performed separately for the development of eGFR $<60 \mathrm{ml} /$ $\mathrm{min} / 1.73 \mathrm{~m}^{2}$ and for the development of proteinuria. 
We performed three sensitivity analyses. Elevated serum ALT levels indicate active inflammation of the liver cells and predict prognosis [20,21]. Because the association of HBsAg status with kidney function may differ by the severity of inflammation in the liver, we stratified the analyses by baseline ALT level (elevated ALT defined as ALT $>41 \mathrm{U} / \mathrm{l}$ for males and ALT $>33 \mathrm{U} /$ 1 for females). In addition, we excluded participants with evidence of liver cirrhosis on ultrasound because patients with liver cirrhosis are more susceptible to developing CKD [22-24]. Finally, we excluded participants who were positive for hepatitis $\mathrm{C}$ virus antibody ( $\mathrm{HCV}$ $\mathrm{Ab})$ because $\mathrm{HCV}$ infection can increase the risk of incident CKD [25, 26].

All statistical analyses were performed with Stata version 14.0 (StataCorp LP, College Station, Texas). Two-sided $P$ values less than 0.05 were considered statistically significant.

\section{Results}

The mean (SD) age of study participants was 37.3 (SD 7.9) years (Table 1). The prevalence of positive $\mathrm{HBsAg}$ serology was $3.7 \%(n=11,209)$. Compared to seronegative individuals, those with positive $\mathrm{HBsAg}$ serology were more likely to be older, male, current smoker, and

Table 1 Participant characteristics by hepatitis B virus infection at baseline $(n=299,913)$

\begin{tabular}{|c|c|c|c|c|}
\hline \multirow[t]{2}{*}{ Characteristics } & \multirow[t]{2}{*}{ Overall } & \multicolumn{2}{|c|}{ Hepatitis B virus infection } & \multirow[t]{2}{*}{$P$ value } \\
\hline & & $\overline{\operatorname{HBsAg}(-)}$ & $\mathrm{HBsAg}(+)$ & \\
\hline Number (\%) & 299,913 & $288,704(96.3)$ & $11,209(3.7)$ & \\
\hline Age, years ${ }^{*}$ & $37.3(7.9)$ & $37.3(7.9)$ & $38.2(7.6)$ & $<0.001$ \\
\hline Men, \% & 56.7 & 56.4 & 63.7 & $<0.001$ \\
\hline Current smoker, \% & 23.6 & 23.6 & 25.1 & $<0.001$ \\
\hline Alcohol intake, g/day ${ }^{\dagger}$ & $5(0-15)$ & $5(0-15)$ & $4(0-13)$ & $<0.001$ \\
\hline Vigorous exercise, $\%^{\ddagger}$ & 14.2 & 14.2 & 15.7 & $<0.001$ \\
\hline Higher education, $\%^{\S}$ & 58.5 & 58.5 & 58.1 & 0.57 \\
\hline $\mathrm{BMI}, \mathrm{kg} / \mathrm{m}^{2^{*}}$ & $23.2(3.2)$ & $23.2(3.2)$ & $23.5(3.1)$ & $<0.001$ \\
\hline $\mathrm{ALT}, \mathrm{U} / \mathrm{I}^{\dagger}$ & $19(14-29)$ & $19(14-29)$ & $26(18-38)$ & $<0.001$ \\
\hline AST, $U / /^{+}$ & $21(18-26)$ & $21(17-26)$ & $25(20-31)$ & $<0.001$ \\
\hline $\mathrm{GGT}, \mathrm{U} / \mathrm{I}^{+}$ & $19(12-33)$ & $19(12-33)$ & $20(13-33)$ & $<0.001$ \\
\hline $\mathrm{eGFR}, \mathrm{ml} / \mathrm{min} / 1.73 \mathrm{~m}^{2^{*}}$ & $88.2(16.6)$ & $88.3(16.7)$ & $86.4(15.2)$ & $<0.001$ \\
\hline Glucose, $\mathrm{mg} / \mathrm{dl}^{*}$ & $93.6(13.7)$ & $93.6(13.7)$ & $93.1(13.6)$ & $<0.001$ \\
\hline Hypertension, \% & 11.7 & 11.7 & 12.0 & 0.37 \\
\hline Diabetes, \% & 2.4 & 2.4 & 2.5 & 0.38 \\
\hline Fatty liver disease, $\%$ & 25.4 & 25.6 & 22.7 & $<0.001$ \\
\hline
\end{tabular}

Values are *mean (standard deviation), ${ }^{\dagger}$ median (interquartile range), or percentage

${ }^{\ddagger}$ Moderate- or vigorous-intensity exercise $\geq 3$ times per week ${ }^{\S}$ College graduate or higher

Abbreviations: ALT alanine aminotransferase, AST aspartate aminotransferase, $B M I$ body mass index, eGFR estimated glomerular filtration rate, GGT gamma-glutamyl transferase frequently engaged in vigorous exercise, to have higher levels of BMI, and liver enzymes, and to have lower alcohol intake, prevalence of fatty liver disease and eGFR levels. The prevalence of hypertension and diabetes were not significantly different between those with and without HBsAg (Table 1).

The mean duration of follow-up was 5.6 years $(1,673,701$ person-years of follow-up). Overall, there were 13,924 new cases of CKD (incidence rate 8.3 per 1000 person-years). By different definitions of CKD, there were 3225 new cases of eGFR $<60 \mathrm{ml} / \mathrm{min} /$ $1.73 \mathrm{~m}^{2}$ and 11,072 new cases of proteinuria during follow-up (incidence rates of 1.9 and 6.6 per 1000 person-years, respectively). Participants who developed CKD were older, had higher levels of liver enzymes and serum glucose, had lower eGFR levels, and were more likely to have other comorbidities, such as hypertension, diabetes, and fatty liver disease at baseline (Additional file 1: Table S1).

There were 609 incident cases of CKD among 11,209 HBsAg positive participants and 13,315 incident cases of CKD among 288,704 HBsAg negative participants (incidence rates of 9.3 and 8.3 per 1000 person-years, respectively; Table 2). In fully adjusted models, the HR comparing HBsAg positive participants to HBsAg negative participants was 1.11 (95\% CI 1.03-1.21; Table 2 and Fig. 2). In additional analyses excluding 215 participants who reported ever having been treated for viral hepatitis at baseline or over follow-up, the fully adjusted HR for incident CKD comparing HBsAg positive participants to HBsAg negative participants was 1.11 (95\% CI $1.02-1.21)$.

When the analyses were performed separately for each CKD component, the association between HBsAg serology and kidney outcomes was limited to incident proteinuria. In fully adjusted models, the HR for incident proteinuria comparing $\mathrm{HBsAg}$ positive to $\mathrm{HBsAg}$ negative participants was 1.23 (95\% CI 1.12-1.35), whereas the corresponding HR for eGFR $<60 \mathrm{ml} / \mathrm{min} / 1.73 \mathrm{~m}^{2}$ was 0.89 (95\% CI 0.73-1.07; Table 2 and Fig. 2). After excluding participants who reported ever having been treated for viral hepatitis at baseline or over follow-up, the corresponding HR for incident proteinuria was 1.23 (95\% CI 1.12-1.35;) and for eGFR $<60 \mathrm{ml} / \mathrm{min} / 1.73 \mathrm{~m}^{2}$ was 0.88 (95\% CI 0.73-1.07).

In sensitivity analyses, the association between HBsAg serology and kidney outcomes was similar in participants with normal and with elevated ALT levels at baseline (Additional file 1: Table S2). Similarly, the findings were essentially unchanged after excluding participants with ultrasound evidence of liver cirrhosis (Additional file 1: Table S3) and after excluding participants with positive $\mathrm{HCV} \mathrm{Ab}$ serology (Additional file 1: Table S4). 
Table 2 Hazard ratios (HR) for incident chronic kidney disease by HBsAg serology $(n=299,913)$

\begin{tabular}{|c|c|c|c|c|}
\hline & $\begin{array}{l}\text { No. of incident cases } \\
\text { (person-years) }\end{array}$ & $\begin{array}{l}\text { Model } 1 \\
\text { HR } \\
(95 \% \mathrm{Cl})\end{array}$ & $\begin{array}{l}\text { Model } 2 \\
\text { HR } \\
(95 \% \mathrm{Cl})\end{array}$ & $\begin{array}{l}\text { Model } 3 \\
\text { HR } \\
(95 \% \text { Cl) }\end{array}$ \\
\hline \multicolumn{5}{|c|}{ eGFR $<60 \mathrm{ml} / \mathrm{min} / 1.73 \mathrm{~m}^{2}$ or proteinuria } \\
\hline HBsAg $(-)$ & $\begin{array}{l}13,315 \\
(1,608,299.2)\end{array}$ & $\begin{array}{l}1.00 \\
\text { (reference) }\end{array}$ & $\begin{array}{l}1.00 \\
\text { (reference) }\end{array}$ & $\begin{array}{l}1.00 \\
\text { (reference) }\end{array}$ \\
\hline HBsAg $(+)$ & $\begin{array}{l}609 \\
(65,401.8)\end{array}$ & $\begin{array}{l}1.07 \\
(0.99-1.16)\end{array}$ & $\begin{array}{l}1.09 \\
(1.00-1.18)\end{array}$ & $\begin{array}{l}1.11 \\
(1.03-1.21)\end{array}$ \\
\hline \multicolumn{5}{|c|}{$\mathrm{eGFR}<60 \mathrm{ml} / \mathrm{min} / 1.73 \mathrm{~m}^{2}$} \\
\hline $\operatorname{HBsAg}(-)$ & $\begin{array}{l}3106 \\
(1,641,700.4)\end{array}$ & $\begin{array}{l}1.00 \\
\text { (reference) }\end{array}$ & $\begin{array}{l}1.00 \\
\text { (reference) }\end{array}$ & $\begin{array}{l}1.00 \\
\text { (reference) }\end{array}$ \\
\hline $\operatorname{HBsAg}(+)$ & $\begin{array}{l}119 \\
(67,044.5)\end{array}$ & $\begin{array}{l}0.91 \\
(0.76-1.09)\end{array}$ & $\begin{array}{l}0.87 \\
(0.72-1.05)\end{array}$ & $\begin{array}{l}0.89 \\
(0.73-1.07)\end{array}$ \\
\hline \multicolumn{5}{|c|}{ Proteinuria } \\
\hline HBsAg $(-)$ & $\begin{array}{l}10,560 \\
(1,621,635.3)\end{array}$ & $\begin{array}{l}1.00 \\
\text { (reference) }\end{array}$ & $\begin{array}{l}1.00 \\
\text { (reference) }\end{array}$ & $\begin{array}{l}1.00 \\
\text { (reference) }\end{array}$ \\
\hline HBsAg $(+)$ & $\begin{array}{l}512 \\
(65,806.8)\end{array}$ & $\begin{array}{l}1.17 \\
(1.07-1.28)\end{array}$ & $\begin{array}{l}1.20 \\
(1.10-1.31)\end{array}$ & $\begin{array}{l}1.23 \\
(1.12-1.35)\end{array}$ \\
\hline
\end{tabular}

Model 1: adjusted for age, sex, center, and baseline eGFR; Model 2: further adjusted for smoking (never, former and current), alcohol intake (g/day), level of education (high school graduate or less and college graduate or higher), physical activity (moderate- or vigorous-intensity physical activity $<3$ times/week and $\geq 3$ times/week), and BMI $\left(\mathrm{kg} / \mathrm{m}^{2}\right)$; and Model 3: further adjusted for hypertension, diabetes, and presence of fatty liver disease

\section{Discussion}

In this large cohort of adults without clinically apparent kidney disease, HBsAg positive participants had a higher incidence risk of CKD compared to HBsAg negative participants. The increased risk was driven by development of proteinuria, although the number of $\mathrm{HBsAg}$ positive participants who developed eGFR $<60 \mathrm{ml} / \mathrm{min} / 1.73 \mathrm{~m}^{2}$ was small. The results were similar in participants with normal or with elevated liver enzyme levels at baseline, and after excluding participants with cirrhosis or with positive HCV antibodies. Since chronic hepatitis B infection is highly prevalent in many countries, our findings suggest that it may be contributing to the global burden of CKD.

The role of hepatitis B infection in the development of CKD is controversial. In a meta-analysis of 4 cohort

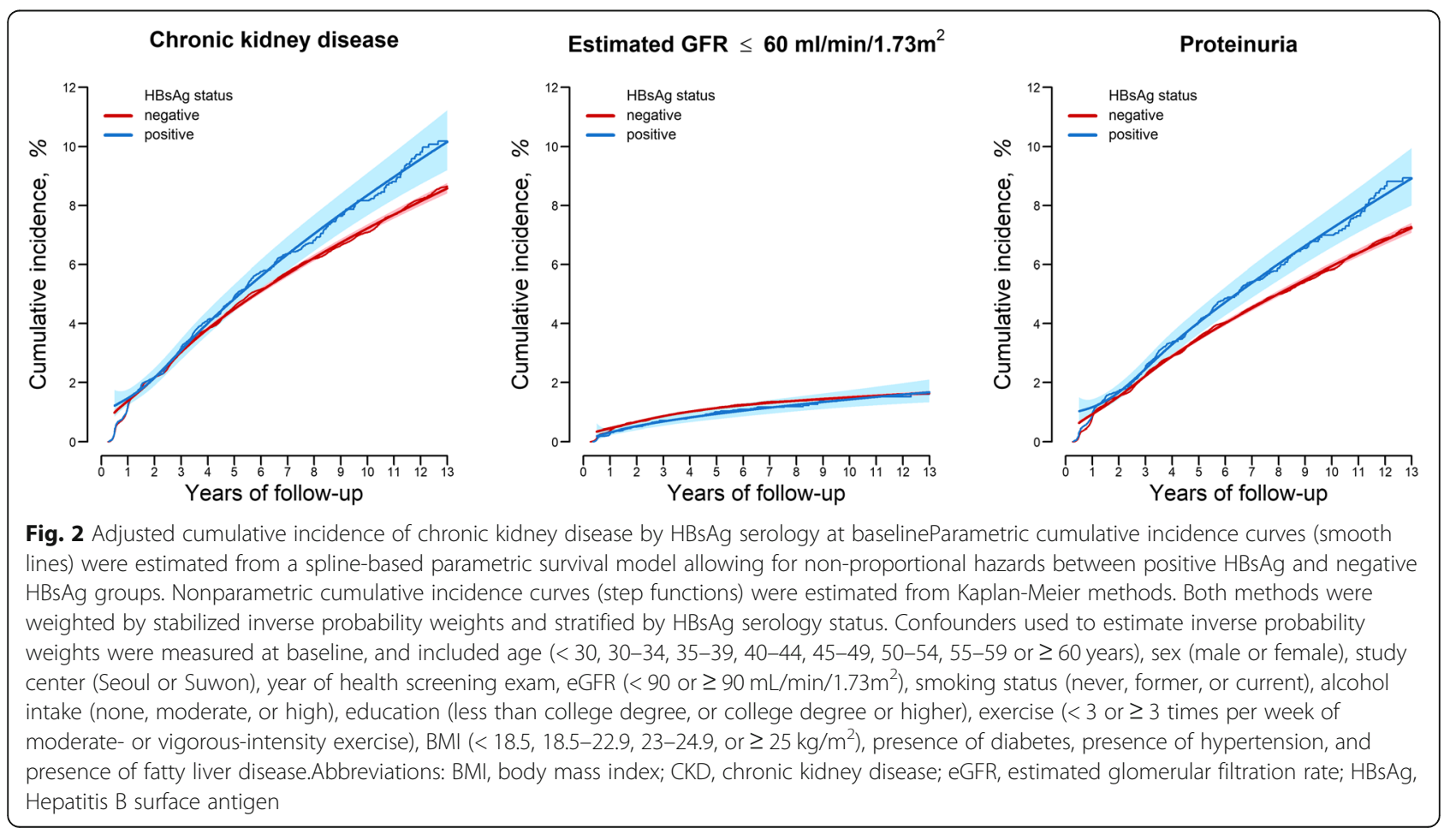


studies, the pooled HR for CKD comparing participants with HBV infection to those without HBV infection was 2.2 (95\% CI 0.95-3.50) [27], but there was substantial heterogeneity across studies. In another meta-analysis of cohort, cross-sectional, and case-control studies in Asian populations, there was no association between $\mathrm{HBsAg}$ serology and reduced eGFR (adjusted risk ratio 0.95; 95\% CI $0.72-1.26$ ) or proteinuria (adjusted risk ratio 1.00; 95\% CI 0.83-1.20) [28].

The largest study in both meta-analyses, a nationwide cohort from Taiwan that used claims data to evaluate the association between chronic HBV infection with incident CKD [6] and incident ESRD [8], found very high HRs (2.58 and 3.85 for CKD and ESRD, respectively). In the large China Kadoori Biobank cohort, participants with HBsAg had higher incidence of CKD compared to participants without HBsAg (adjusted HR 1.37; 95\% CI 1.18-1.60). CKD was defined using ICD-10 codes from national health insurance system claims data [7]. Claims-based studies may have limited sensitivity to detect asymptomatic HBV infection, and are likely to capture more severe, symptomatic cases of HBV infection and kidney diseases. Claims-based data have also a limited ability to identify participants with prevalent CKD at baseline and with asymptomatic or early stages of chronic kidney disease, and they are prone to surveillance bias as patients with a diagnosis of HBV infection may be more likely to be tested for kidney function, and vice versa. Furthermore, using ICD codes does not distinguish whether incident CKD was mainly caused by reduced eGFR or by the development of proteinuria. In our study, we used repeated measurements of eGFR and proteinuria in participants undergoing regular health screening exam to define incident CKD, which allowed us to evaluate the different mechanisms of developing CKD separately and to identify CKD in otherwise healthy participants.

In a smaller cohort of health screening examinees in China, there was no association between the presence of anti-HBc antibodies and the incidence of reduced eGFR, proteinuria, or CKD over a 5-year period. The presence of anti-HBc antibodies, however, cannot differentiate resolved HBV infections from chronic active HBV infections [9]. In our analysis, we used a positive HBsAg test as a marker of exposure. In East Asian countries, including China and Korea, HBV is most often transmitted vertically at birth, and a positive HBsAg test in adults most likely represents chronic HBV infection [29].

In three cross-sectional studies conducted also in East Asian countries, positive HBsAg serology was not associated with an increased risk of prevalent proteinuria $[11,13,30]$. In contrast, the significant association between HBsAg serology and incidence of CKD in the present study was due to incident proteinuria, with no clear association between $\mathrm{HBsAg}$ serology and the incidence of reduced eGFR. Our prospective study suggests that the increased incidence of CKD in HBsAg positive subjects is mainly due to an increased incidence of proteinuria. This finding is also supported by the fact that HBV-associated nephropathies, such as membranous nephropathy and membranoproliferative glomerulonephritis, most commonly present with proteinuria or nephrotic syndrome.

The prevalence of CKD among HBsAg positive subjects ranges from 0.4 to $11.4 \%$, but it tends to be higher among those with elevated ALT [10, 11, 31]. In our study, the incidence of CKD was higher in participants with elevated ALT levels (12.2 per 1000 person-years) than in participants with normal ALT levels at baseline (7.7 per 1000 person-years). HBV-associated nephropathy is more common when there is active replication of the virus or active inflammation in liver cells (immune tolerant or immune clearance phase) than when the viral burden and liver enzyme levels are low (inactive carrier phase) [3]. In our study, however, the association between positive HBV serology and incidence of CKD was similar across baseline ALT level categories, suggesting that the risk of kidney damage is elevated in all stages of HBV infection, even in the absence of active viral replication or inflammation.

Our findings are consistent with those from basic research studies. HBV-associated nephropathy is mainly due to immunological processes, particularly immune complex deposition in the kidney [3]. The circulating antigen-antibody complex formed at the acute exposure to HBV may continue to damage the glomerular structure even when the virus is not actively replicating, leading to proteinuria. Indeed, the most common types of HBV-associated nephropathy, such as membranous nephropathy and membranoproliferative glomerulonephritis, involve proteinuria. In addition to immunologic mechanisms, the virus may damage the kidney either directly or through apoptosis. HBV DNA has been identified both in glomerular and in tubular cells $[3,5]$, and it may promote apoptosis of renal tubular cells through upregulation of the Fas pathway [32]. In our study, we did not have histologic diagnosis of the type of kidney damage or information about potential mechanistic pathways. Additional studies are needed to better understand the mechanisms underlying the association between HBV infection and kidney damage.

There are a few limitations to our study. We used urine dipsticks to identify proteinuria, but dipsticks may not be sensitive enough to detect low levels of proteinuria [33]. Furthermore, we defined CKD using a single measurement of eGFR and/or proteinuria, whereas the current guideline defines CKD as abnormalities or 
markers of damage for at least 3 months [34]. These sources of measurement error, however, are random with respect to exposure and would tend to underestimate the underlying associations. Second, our study may not have been long enough to see the effect of HBV on reduction in eGFR, especially since our participants were relatively young and healthy with stable liver function and low prevalence of underlying comorbidities. Third, we did not have information on the presence of hepatitis B e-antigen, on HBV DNA titers, or detailed history on HBV treatment (although we know which participants received treatment for viral hepatitis from self-reports). Treatment with oral antiviral agents may decrease renal function in chronic hepatitis $\mathrm{B}$ patients, whereas their effects on the development of proteinuria is less certain $[35,36]$ Tenofovir, which may cause both reduction in renal function and tubular damage, was introduced to Korea in 2012 and is unlikely to be the cause of higher incidence of proteinuria in HBsAg positive participants in our study. In addition, excluding participants who reported having ever been treated for viral hepatitis at baseline or over follow-up did not change our results. Finally, our study population was comprised of Korean men and women participating in regular health screening exams and our findings may not generalize to other race/ethnicity groups.

There are also several strengths to the study. In addition to the large sample size, our study participants were relatively young and healthy. As a result, the association between HBsAg and incident CKD is less likely to be confounded by comorbidities and medication use than studies conducted in elderly cohorts. In addition, detailed health screening information on anthropometric measures, lifestyle behaviors, medical history, and laboratory tests allowed us to account for multiple potential confounders. Finally, we measured urine protein in addition to eGFR and we were able to evaluate the association of $\mathrm{HBsAg}$ with eGFR and with proteinuria separately.

\section{Conclusion}

In conclusion, our study provides evidence to support an association between HBsAg positive serology and higher incidence of CKD. More specifically, we provide novel evidence that this association is due to a higher incidence of proteinuria in HBsAg positive compared to HBsAg negative subjects. Studies with detailed information on HBV replication status, HBV treatment history, and longer follow-up are needed to provide further insight to the association between HBV and CKD. Because patients with both chronic liver disease and CKD have much poorer prognosis and higher mortality than those with either condition, prevention and early detection of kidney disease is essential in patients with chronic HBV infection.

\section{Additional files}

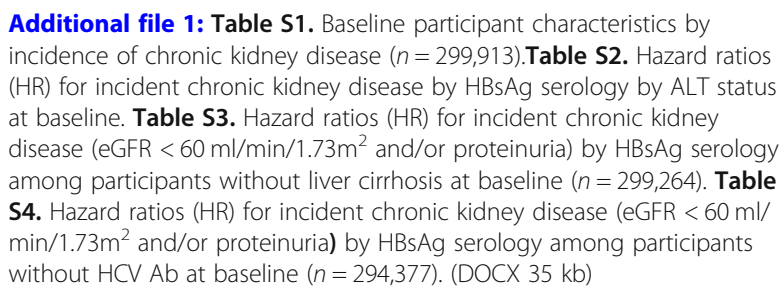

\section{Abbreviations}

anti-HBc antibody: Antibody to hepatitis B core antigen; BMl: Body Mass Index; CKD: Chronic Kidney Disease; eGFR: Estimated Glomerular Filtration Rate; ESRD: End-stage Renal Disease; HBsAg: Hepatitis B surface Antigen; HBV: Hepatitis B Virus; HCV: Hepatitis C Virus

\section{Acknowledgements}

None.

\section{Funding}

The authors received no specific funding for this work.

\section{Availability of data and material}

Unfortunately, the data are not available to be shared publicly as we do not have IRB permission for distributing the data. However, data are available from the Kangbuk Samsung Health Study whose authors may be contacted through the corresponding author.

\section{Authors' contributions}

Concept and design: YSH, SR. Acquisition of data: SR, YC, M-JK, DZ, HS. Analysis and interpretation of data: YSH, YC, MC-A, DZ, TS, ML, RP-B, EG. Drafting of manuscript: YSH, SR, EG. Critical revision: YSH, SR, YC, MC-A, M-JK, DZ, TS, $M L, R P-B, H S, J C, E G$

All authors have read and approved the manuscript.

\section{Ethics approval and consent to participate}

This study was approved by the Kangbuk Samsung Hospital Institutional Review Board that waived the requirement for informed consent as we only used de-identified data obtained as part of routine health screening exams.

Consent for publication

Not applicable.

Competing interests

The authors have no competing interests to declare.

\section{Publisher's Note}

Springer Nature remains neutral with regard to jurisdictional claims in published maps and institutional affiliations.

\section{Author details}

${ }^{1}$ Departments of Epidemiology and Medicine, and Welch Center for Prevention, Epidemiology, and Clinical Research, Johns Hopkins University Bloomberg School of Public Health, Baltimore, MD, USA. ${ }^{2}$ Center for Cohort Studies, Total Healthcare Center, Kangbuk Samsung Hospital, Sungkyunkwan University School of Medicine, Seoul, Republic of Korea. ${ }^{3}$ Department of Health Sciences and Technology, Samsung Advanced Institute for Health, Sciences and Technology, Sungkyunkwan University, Seoul, Republic of Korea. ${ }^{4}$ Department of Occupational and Environmental Medicine, Kangbuk Samsung Hospital, Sungkyunkwan University School of Medicine, Seoul, Republic of Korea. ${ }^{5} \mathrm{Ciccarone}$ Center for the Prevention of Heart Disease, Department of Cardiology, Johns Hopkins Medical Institutions, Baltimore, MD, USA. ${ }^{6}$ Bellvitge University Hospital, Barcelona, Spain. ${ }^{7}$ RTI Health 
Solutions, Pharmacoepidemiology and Risk Management, Barcelona, Spain. ${ }^{8}$ Department of Laboratory Medicine, Kangbuk Samsung Hospital, Sungkyunkwan University, School of Medicine, Seoul, South Korea. ${ }^{9}$ Division of Nephrology, Department of Medicine, Johns Hopkins University School of Medicine, Baltimore, MD, USA. ${ }^{10}$ National Center for Epidemiology, Carlos III Institute of Health and Consortium for Biomedical Research in Epidemiology and Public Health (CIBERESP), Madrid, Spain. ${ }^{11}$ Department of Family Medicine, Kangbuk Samsung Hospital and Sungkyunkwan University School of Medicine, Seoul, Republic of Korea.

Received: 3 September 2018 Accepted: 23 November 2018 Published online: 11 December 2018

\section{References}

1. Lozano R, Naghavi M, Foreman K, Lim S, Shibuya K, Aboyans V, et al. Global and regional mortality from 235 causes of death for 20 age groups in 1990 and 2010: a systematic analysis for the global burden of disease study 2010. Lancet. 2012;380(9859):2095-128.

2. Cacoub P, Saadoun D, Bourliere M, Khiri H, Martineau A, Benhamou Y, et al. Hepatitis B virus genotypes and extrahepatic manifestations. J Hepatol. 2005;43(5):764-70

3. Bhimma R, Coovadia HM. Hepatitis B virus-associated nephropathy. Am J Nephrol. 2004;24(2):198-211.

4. Lai KN, Li PK, Lui SF, Au TC, Tam JS, Tong KL, et al. Membranous nephropathy related to hepatitis B virus in adults. N Engl J Med. 1991; 1991(324):1457-63.

5. Lai KN, Ho RT, Tam JS, Lai FM. Detection of hepatitis B virus DNA and RNA in kidneys of HBV related glomerulonephritis. Kidney Int. 1996;50(6):1965-77.

6. Chen YC, Su YC, Li CY, Hung SK. 13-year nationwide cohort study of chronic kidney disease risk among treatment-naive patients with chronic hepatitis B in Taiwan. BMC Nephrol. 2015;16:110.

7. Si J, Yu C, Guo Y, Bian Z, Qin C, Yang L, et al. Chronic hepatitis B virus infection and risk of chronic kidney disease: a population-based prospective cohort study of 0.5 million Chinese adults. BMC Med. 2018;16(1):93.

8. Chen YC, Su YC, Li CY, Wu CP, Lee MS. A nationwide cohort study suggests chronic hepatitis $B$ virus infection increases the risk of end-stage renal disease among patients in Taiwan. Kidney Int. 2015;87(5):1030-8.

9. Kong X-L, Ma X-J, Su H, Xu D-M. Relationship between occult hepatitis B virus infection and chronic kidney disease in a Chinese population-based cohort. Chronic Diseases and Translational Medicine. 2016;2(1):55-60.

10. Cai J, Fan X, Mou L, Gao B, Liu X, Li J, et al. Association of reduced renal function with hepatitis $B$ virus infection and elevated alanine aminotransferase. Clin J Am Soc Nephrol. 2012;7(10):1561-6.

11. Lee JJ, Lin MY, Yang YH, Lu SN, Chen HC, Hwang SJ. Association of hepatitis $C$ and $B$ virus infection with CKD in an endemic area in Taiwan: a crosssectional study. Am J Kidney Dis. 2010;56(1):23-31.

12. Huang JF, Chuang WL, Dai CY, Ho CK, Hwang SJ, Chen SC, et al. Viral hepatitis and proteinuria in an area endemic for hepatitis $B$ and $C$ infections: another chain of link? J Intern Med. 2006;260(3):255-62.

13. Ishizaka N, Ishizaka Y, Seki G, Nagai R, Yamakado M, Koike K. Association between hepatitis $B / C$ viral infection, chronic kidney disease and insulin resistance in individuals undergoing general health screening. Hepatol Res. 2008;38(8):775-83.

14. Pipili CL, Papatheodoridis GV, Cholongitas EC. Treatment of hepatitis B in patients with chronic kidney disease. Kidney Int. 2013;84(5):880-5.

15. Chang Y, Ryu S, Choi Y, Zhang Y, Cho J, Kwon MJ, et al. Metabolically healthy obesity and development of chronic kidney disease: a cohort study. Ann Intern Med. 2016;164(5):305-12.

16. Chang Y, Kim BK, Yun KE, Cho J, Zhang Y, Rampal S, et al. Metabolicallyhealthy obesity and coronary artery calcification. J Am Coll Cardiol. 2014; 63(24):2679-86.

17. Chang Y, Jung HS, Yun KE, Cho J, Cho YK, Ryu S. Cohort study of nonalcoholic fatty liver disease, NAFLD fibrosis score, and the risk of incident diabetes in a Korean population. Am J Gastroenterol. 2013;108(12):1861-8.

18. Manjunath G, Sarnak MJ, Levey AS. Prediction equations to estimate glomerular filtration rate: an update. Curr Opin Nephrol Hypertens. 2001; 10(6):785-92.

19. Royston P, Parmar MK. Flexible parametric proportional-hazards and proportional-odds models for censored survival data, with application to prognostic modelling and estimation of treatment effects. Stat Med. 2002; 21(15):2175-97.
20. Terrault NA, Lok ASF, McMahon BJ, Chang KM, Hwang JP, Jonas MM, et al. Update on prevention, diagnosis, and treatment of chronic hepatitis B: AASLD 2018 hepatitis B guidance. Hepatology (Baltimore, Md). 2018;67(4): 1560-99.

21. Rotman $Y$, Brown TA, Hoofnagle $J H$. Evaluation of the patient with hepatitis B. Hepatology. 2009:49(5 Suppl):S22-7.

22. Gines P, Schrier RW. Renal failure in cirrhosis. N Engl J Med. 2009;361(13): 1279-90.

23. Gonwa TA, Wadei HM. Kidney disease in the setting of liver failure: core curriculum 2013. Am J Kidney Dis. 2013;62(6):1198-212.

24. Slack A, Yeoman A, Wendon J. Renal dysfunction in chronic liver disease. Crit Care. 2010;14(2):214

25. Fabrizi F, Verdesca S, Messa P, Martin P. Hepatitis C virus infection increases the risk of developing chronic kidney disease: a systematic review and meta-analysis. Dig Dis Sci. 2015;60(12):3801-13.

26. Cacoub P, Desbois AC, Isnard-Bagnis C, Rocatello D, Ferri C. Hepatitis C virus infection and chronic kidney disease: time for reappraisal. J Hepatol. 2016; 65(1 Suppl):S82-s94.

27. Fabrizi F, Donato FM, Messa P. Association between hepatitis B virus and chronic kidney disease: a systematic review and meta-analysis. Ann Hepatol. 2017;16(1):21-47.

28. Cai QC, Zhao SQ, Shi TD, Ren H. Relationship between hepatitis B virus infection and chronic kidney disease in Asian populations: a meta-analysis. Ren Fail. 2016:38(10):1581-8.

29. The Korean Association for the Study of the L. KASL clinical practice guidelines: management of chronic hepatitis B. Clin Mol Hepatol. 2016:22(1): $18-75$.

30. Zeng Q, Gong Y, Dong S, Xiang H, Wu Q. Association between exposure to hepatitis B virus and chronic kidney disease in China. The Journal of international medical research. 2014;42(5):1178-84.

31. Amet S, Bronowicki JP, Thabut D, Zoulim F, Bourliere M, Mathurin P, et al. Prevalence of renal abnormalities in chronic HBV infection: the HARPE study. Liver Int. 2015:35(1):148-55.

32. Deng CL, Song XW, Liang HJ, Feng C, Sheng YJ, Wang MY. Chronic hepatitis B serum promotes apoptotic damage in human renal tubular cells. World J Gastroenterol. 2006;12(11):1752-6.

33. Lim D, Lee DY, Cho SH, Kim OZ, Cho SW, An SK, et al. Diagnostic accuracy of urine dipstick for proteinuria in older outpatients. Kidney research and clinical practice. 2014;33(4):199-203.

34. KVOQI. Clinical practice guidelines for chronic kidney disease: evaluation, classification, and stratification. Am J Kidney Dis. 2002;39(2 Suppl 1):S1-266.

35. Mauss S, Berger F, Filmann N, Hueppe D, Henke J, Hegener P, et al. Effect of HBV polymerase inhibitors on renal function in patients with chronic hepatitis B. J Hepatol. 2011;55(6):1235-40.

36. Shin JH, Kwon HJ, Jang HR, Lee JE, Gwak GY, Huh W, et al. Risk factors for renal functional decline in chronic hepatitis B patients receiving Oral antiviral agents. Medicine (Baltimore). 2016;95(1):e2400

Ready to submit your research? Choose BMC and benefit from:

- fast, convenient online submission

- thorough peer review by experienced researchers in your field

- rapid publication on acceptance

- support for research data, including large and complex data types

- gold Open Access which fosters wider collaboration and increased citations

- maximum visibility for your research: over $100 \mathrm{M}$ website views per year

At $\mathrm{BMC}$, research is always in progress.

Learn more biomedcentral.com/submissions 